\title{
ABET Accreditation: An Engineering Experience from Sultan Qaboos University, Oman
}

\author{
Hassan, Hossam ${ }^{a}$ and Al-Jabri, Khalifa ${ }^{a}$
}

${ }^{a}$ Department of Civil and Architectural Engineering, Sultan Qaboos University, Oman,

\begin{abstract}
The Accreditation Board for Engineering and Technology (ABET) accredits college and university programs in engineering under the Engineering Accreditation Commission (EAC). The process follows Engineering Criteria (EC) 2000, which focuses on outcomes (what is learned) rather than what is taught. This paper presents an overview of the processes developed by the civil engineering (CE) program at Sultan Qaboos University to satisfy ABET Criteria 2, 3, and 4. The program had a successful accreditation visit in November 2013. Program educational objectives (PEOS) were developed. A review and revision process for PEOs was also developed. ABET student outcomes (SOs) were adopted by the CE program. SOs were broken into outcome elements. Key performance indicators were developed for each outcome element, according to the six levels of Bloom's taxonomy for cognitive domain. The process used direct indicators from student work as well indirect survey instruments. The program has developed a detailed and systematic approach for assessment of SOs with feedback and follow-up on implementation of actions for continuous improvement. Planning for the next accreditation cycle of SO assessment proved valuable, as the new accreditation committee started executing an already laid out work plan.
\end{abstract}

Keywords: ABET; Accreditation; Civil Engineering; Oman. 


\section{Introduction}

The Accreditation Board for Engineering and Technology (ABET) accredits college and university programs in the disciplines of applied science, computing, engineering, and engineering technology at the associate, bachelor, and master degree levels. It is driven by 35 member societies who set the standards for the accreditation process. ABET accreditation provides students, employers, and the society confidence that a program meets the quality standards that produce graduates prepared to enter a global workforce (ABET 2016). ABET requires a program to satisfy eight criteria and one program criterion under the Engineering Accreditation Commission (EAC) (ABET 2012). Criterion 2: Program Educational Objectives (PEO), Criterion 3: Student Outcome (SO), and Criterion 4: Continuous Improvement can be considered the core of the accreditation process, as they require special attention in documentation and preparation for accreditation.

Several programs have reported their experiences in accreditation. Soundarajan (2002) reported the experience of the Computer Science and Engineering program at Ohio State University, under ABET Engineering Criteria (EC) 2000. A recent report by Sundararajan (2014) presented the experience of the Mechanical Engineering at Iowa State University. Instructors were asked to set a criterion that reflects the demonstration of the particular outcome. A mix of course activities already in-place were used for evaluation. Rubrics were also used for laboratory reports and design projects. Faculty involvement was maximized while minimizing the efforts, resulting in a sustainable process.

Felder and Brent (2003) and Mourtos (2003) presented the work of Besterfield-Sacre et al. (2000) on defining outcome elements and attributes. Besterfield-Sacre et al. (2000) suggested breaking each outcome into separate elements. They suggested that some outcomes are easier to break than others; elements are literally extracted from these outcomes. Outcome attributes can be written as actions that explicitly demonstrate mastery of the abilities specified in an outcome or outcome element. Attributes were defined for the six levels of Bloom's taxonomy for the cognitive domain and the valuation levels of Krathwohl's taxonomy of affective domain.

This paper presents an overview of the ABET accreditation process for the civil engineering (CE) program at Sultan Qaboos University, in Oman. A successful accreditation visit took place in November 2013. The focus in this paper is on the development and documentation process for satisfying ABET EAC Criteria 2, 3, and 4.

\section{Program Educational Objectives}

The civil engineering program at Sultan Qaboos University has accepted and implemented the use of the term "objectives" as described in the ABET Criteria (ABET 2012). Hence, 
the Program Educational Objectives (PEOs) are broad statements that describe what graduates are expected to attain within a few years of graduation. The major constituencies of the CE program included: (1) Engineering faculty, (2) Current Engineering students, (3) Alumni, (4) Employers, and (5) Industrial Advisory Board (IAB). An external examiner was included as a stakeholder, as he is an experienced academic in curricular matters, who is selected by the vice chancellor's office for the assessment of curricular and other activities in the program.

The first set of PEOs were developed in 2001 by soliciting feedback from stakeholders on PEOs. This resulted in a revised version of PEOs presented in the first ABET substantial equivalency accreditation visit in 2006. The PEOs went through another cycle of review and revision from 2008 to 2012. The current PEOs for the CE program are to prepare civil engineering graduates who will: (1) Design, construct, and maintain civil engineering systems using technical knowledge, design principles, and modern engineering tools; (2) Use their communication, leadership, and team-work skills effectively, and deal responsibly with the ethical, professional and social issues; and (3) Stay current through self-learning experiences, professional development, or postgraduate studies.

Prior to October 2012, employers were asked to review PEOs and the degree at which PEOS were being attained was assessed through surveys of alumni and employers. On October 2012, ABET introduced changes to Criteria 2 and 4 for the 2013-14 review cycle. The assessment of PEOs was removed and a documented process, systematically utilized, for periodic review and revision of the program PEOs through the constituents was required. As a result of these changes, a process for systemic review and revision of PEOs using input from all constituents in line with the institutional mission was developed prior to the 2013 accreditation visit. The developed review process for PEOs was a three-year cycle, which normally starts at the beginning of the academic year in the fall and takes one year to complete. A period of three years was expected be reasonable to keep up with relatively infrequent changes in constituency needs.

The systemic review and revision process starts by reviewing the PEOs by the department's accreditation committee to be in consistency with ABET criteria and the institutional mission, which is reflected in the college's mission, and the department's mission. SOs are also taken into account. Alumni and employers are invited to review the PEOs. Results are analyzed by the accreditation committee and are passed to the department board for review. The revisions are sent to the external examiner, to obtain an outside perspective, as well as to IAB members. The recommendations are implemented by the accreditation committee and reviewed by the department board for final approval. PEOs are then updated, if necessary. The information is passed to the curriculum committee for implementing any changes to the educational practice or strategies. The changes in PEOs may also affect the SOs. A retrospective discussion of PEOs with graduating students 
takes place at the end of each spring semester. The constituent input to the process is shown in Table 1.

Table 1. Constituent input to PEO.

\begin{tabular}{lll}
\hline Input Method & Schedule & Constituent \\
\hline Accreditation Committee & three times (during review process) & 1. Eng. faculty \\
Departmental Board & Twice (during review process) & 1. Eng. faculty \\
Student exit interview & Every year & 2. Current students ${ }^{\mathrm{a}}$ \\
Alumni survey & Every three years & 3. Alumni \\
Employer survey & Every three years & 4. Employer \\
IAB meetings & Every three years & 5. IAB \\
Email correspondence & Every three years & 6. External examiner \\
\hline${ }^{\mathrm{a}}$ retrospective discussion of PEOs and students' career paths; ${ }^{\mathrm{b}}$ or annual visit.
\end{tabular}

\section{Student Outcomes and Continuous Improvement}

Student outcomes (SOs) are what students are expected to know and be able to do by the time of graduation, in terms of skills, knowledge, and behaviors (ABET 2012). As recommended by the CE faculty members, ABET student outcomes (a) through (k) (ABET 2012) have been adopted as the CE program outcomes. SOs support the PEOs of the program. The association of SOs (b), (d), (e), and (i), as an example, with PEOs is shown in Table 2.

Table 2. Example of association of PEOs and SOs.

\begin{tabular}{|c|c|c|c|}
\hline Student Outcome (SO) & $\begin{array}{c}\text { PEO } \\
1\end{array}$ & $\begin{array}{c}\text { PEO } \\
2\end{array}$ & $\begin{array}{c}\text { PEO } \\
3\end{array}$ \\
\hline $\begin{array}{l}\text { (b) an ability to design and conduct experiments, as well as to } \\
\text { analyze and interpret data. }\end{array}$ & $\checkmark$ & & \\
\hline (d) an ability to function on multidisciplinary teams. & & $\checkmark$ & \\
\hline (e) an ability to identify, formulate, and solve eng. problems. & $\checkmark$ & & \\
\hline $\begin{array}{l}\text { (i) a recognition of the need for, and an ability to engage in life- } \\
\text { long learning. }\end{array}$ & & & $\checkmark$ \\
\hline
\end{tabular}


Each outcome was defined by elements or different abilities specified in the outcome. In several outcome elements, a set of lower level attributes or performance indicators (PIs) were defined for each element to clearly define the actions that explicitly demonstrate the mastery of the abilities specified. This was done in order for the SOs to be communicated to the students and measured in a consistent and reliable manner in the assessment process. Table 3 shows the outcome elements and PIs for SO (b), as an example.

Table 3. Example of student outcomes, element and performance indicators.

\begin{tabular}{|c|c|}
\hline Student Outcome & Performance Indicators \\
\hline $\begin{array}{l}\text { (b) an ability to } \\
\text { design and conduct } \\
\text { experiments, as well } \\
\text { as to analyze and } \\
\text { interpret data. }\end{array}$ & $\begin{array}{l}\text { b.1 Design experiments, given the stated objectives: } \\
\text { - Choose testing parameters. } \\
\text { - Choose appropriate equipment. } \\
\text { - Determine appropriate number of samples. } \\
\text { - Describe steps for performing the experiment. } \\
\text { b.2 Conduct experiments: } \\
\text { - Become familiar with the equipment. } \\
\text { - } \text { Follow the proper and safe procedure to collect data. } \\
\text { b.3 Process Data: } \\
\text { - Carry out necessary calculations. } \\
\text { - Check data variability. } \\
\text { - Tabulate and plot results. } \\
\text { b.4 Analyze data and Interpret results: } \\
\text { - Identify trends. } \\
\text { - Compare with specification or predictive equations. } \\
\text { - Draw conclusions. }\end{array}$ \\
\hline
\end{tabular}

\subsection{Assessment Methods and Plan for the Next accreditation Visit}

The assessment methods for SOs were divided into direct and indirect methods. The direct assessment relied on student coursework to provide quantitative data; and included exam questions, term papers or projects, laboratory reports, field and laboratory observation on conducting experiments, teamwork, use of modern equipment, and senior design project reports and presentation. On the other hand, the indirect assessment collected data from faculty members in the form of core course report comments and recommendations as well as student exit survey for graduating students. Core course reports were submitted every semester, and have been organized to include comments on: any shortcomings in students' previous knowledge of engineering subjects, general knowledge, skills,...etc; course learning objectives; student outcome assessment (if done in the course); implementation of actions for continuous improvement; and instructor's recommendations. The instructor's 
recommendations were further divided into recommendations related to: SOs, department or curriculum committee, or course management (course specific).

Figure 1 shows the SO assessment process. Core courses were mapped to PIs through meetings with course instructors and review of the learning objectives of the courses. From the mapping of courses to PIs, sampled courses were assessed using direct assessment methods. Outcome assessment was conducted in three cycles for the ABET six-year accreditation period. Each cycle was comprised of one fall and one spring semesters. In each cycle, every PI was assessed in selected number of courses. The assessment of SOs relied on both the course component grades (specific questions in exams, reports, etc...) as well as on rubrics (for laboratory reports, presentations, and capstone design project). A simple Excel sheet was used to compute the percentage of students achieving the target, typically set at $70 \%$ of the students achieving $70 \%$ or higher grade in the assessed course component. Assessment results from different courses for each PI and SO were presented in a matrix. The average results were also presented graphically for each assessment cycle. The student exit survey was conducted at the end of the spring semester, and provided two types of information: students' perception of their acquired abilities, as described by PIs, and additional comments related to SOs or to the program in general. The survey requested rating on a 1-4 point scale, from disagree to strongly agree. The target was set at $70 \%$ of responses indicating agree or strongly agree for a particular PI. Indirect assessment results from exit surveys on PIs (SOs) were graphically presented with the direct assessment results.

A plan for the next six-year cycle of activities for SOs was prepared. Year 1 consists of review of PIs and mapping of courses versus PIs, as well review of assessment sampling plan. Data collection should be conducted in year 2 for all SOs. Evaluation of data should be in year 3. Actions should be implemented prior to year 4. Years 5 and 6 are similar to years 2 and 3 . This cycle should be repeated every six years. The plan proved valuable as a road map for the new accreditation committee working on the next accreditation cycle.

\subsection{Evaluation and Actions for Improvement}

The evaluation of SO assessment results, and recommendation of actions for improvement for each assessment cycle (Figure 1) started from the Accreditation Committee, which met for this purpose once at the end of each semester. In the fall semester, the committee met to discuss the core course reports. The recommendations were reviewed and revised. Another similar meeting was held at the end of the spring semester with more tasks at hand. Direct and indirect assessment data were analyzed. Core course reports of the spring semester were discussed. The committee finally performed a review and revision of the recommendations for the entire year. At the end of the spring semester, a general meeting 
for all the CE faculty members was held to discuss and revise the proposed actions for improvement. Additional actions related to the program were discussed, ending with the approval of the department board. Feedback was provided in the form of recommendations: (1) to instructors teaching core courses covering the relevant PI or SO, (2) to the department or curriculum committee, and (3) specific to a course, for next offering. 


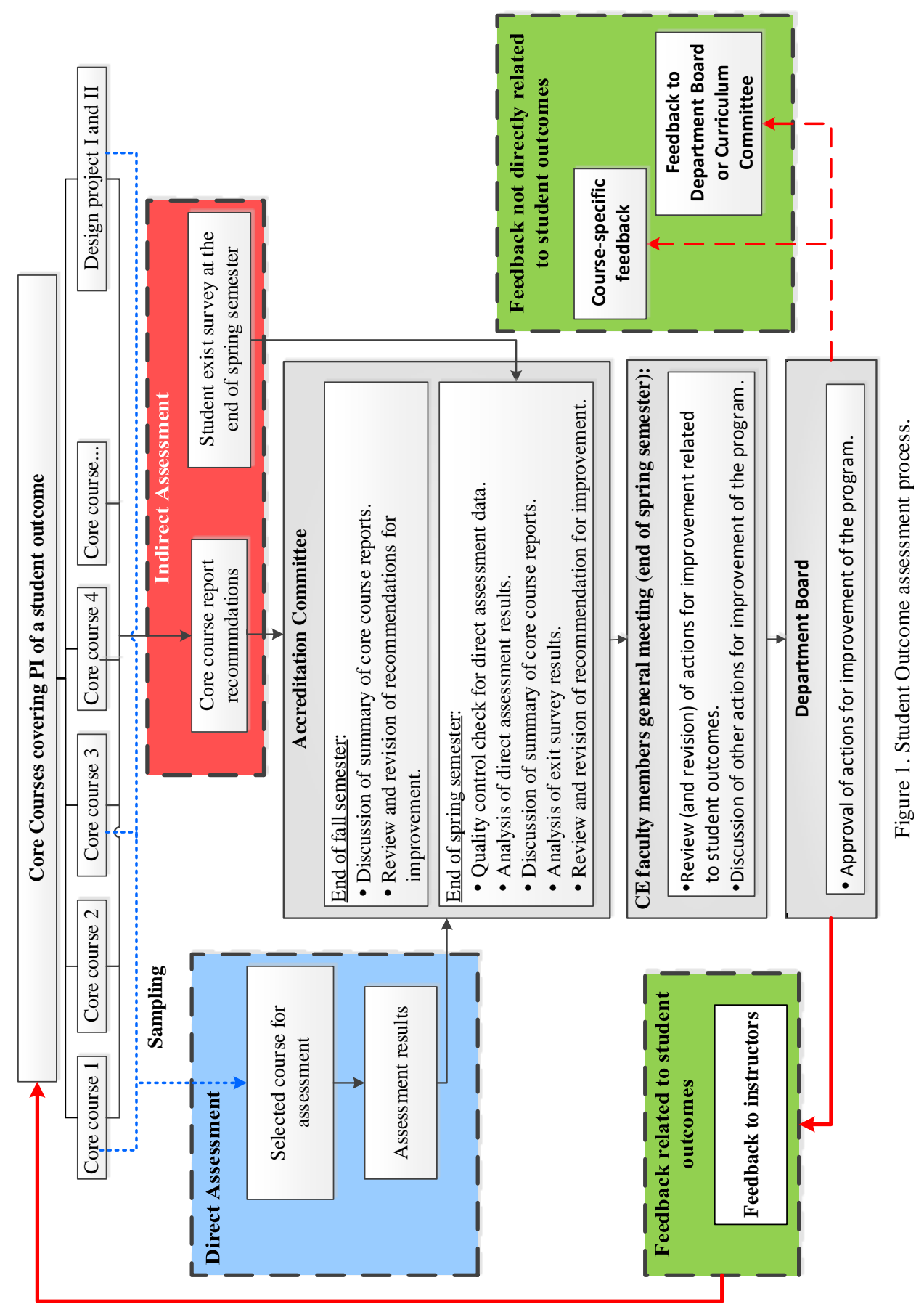

This work is licensed under a Creative Commons License CC BY-NC-ND 4.0 Editorial Universitat Politècnica de València 


\section{Conclusions}

This paper described an overview of the processes developed by the civil engineering program at Sultan Qaboos University to satisfy ABET EAC criteria 2, 3, and 4. A successful accreditation visit took place in November 2013. This visit was preceded by a substantial equivalency visit in 2006. Program educational objectives have gone through several major revisions by the stakeholders since first developed in 2001. Finally, a process for review and revision for the program educational objectives has been developed.

ABET Student Outcomes (a) to (k) were adopted as the program SOs. The program has developed a detailed and systematic approach for assessment of SOs. SOs were broken into outcome elements. Key performance indicators were developed for each outcome element according to the six levels of Bloom's taxonomy for cognitive domain. The process used direct indicators from student work as well indirect survey instruments. Rubrics were used for assessing laboratory reports, presentation, and the capstone design project. Within the process, data were analyzed to identify necessary changes for continuous improvement. Feedback was provided and implementation of actions for improvement was also monitored. Planning for the next accreditation cycle of SO assessment proved valuable, as it paved the way for the new accreditation committee.

\section{References}

ABET (2012). Criteria for Accrediting Engineering Programs, Effective for Review during the 2013-2014 Accreditation Cycle. Baltimore, MD.

ABET (2016, January 20). Accreditation Board for Engineering and Technology: http://www.abet.org/about-abet/

Besterfield-Sacre, M., Shuman, L.J., Wolfe, H., Atman, C.J., McGourty, J., Miller, R.L., Olds, B.M., \& Rogers, G. M. (2000). Defining the Outcomes: A Framework for EC2000. IEEE Transactions on Education, 43(2), 100-110.

Fleder, R.M., \& Brent, R. (2003). Designing and teaching courses to satisfy the ABET engineering criteria. Journal of Engineering Education, 92(1), 7-25.

Mourtos, N. J. (2003). A Sustainable, systematic, process for continuous program improvement. Global Journal of Engineering Education, 10(2), 191-204.

Soundarajan, N. (2002). Preparing for accreditation under EC 2000: an experience report. Journal of Engineering Education, 91(1), 117-123.

Soundararajan, S. (2014). A strategy for sustainable student outcomes assessment for a Mechanical Engineering program that maximizes faculty engagement. Mechanical Engineering Conference Presentations, Papers, and Proceedings. Paper 54. Retrieved from: http://lib.dr.iastate.edu/me_conf/54 